\title{
Back Problems Due To Heavy Backpacks in School Children
}

\author{
Avantika Rai ${ }^{1,}$ Shalini Agarawal ${ }^{2}$ \\ 1Research Scholar,2Assistant Professor,Department of Human Development \&Family Studies, School for Home \\ Science Babashaheb Bhim Rao Ambedakar(A Central University)Lucknow India
}

\begin{abstract}
Students and backpacks are a common sight today. Backpacks come in all sizes, colors, fabrics, and shapes and help children's of all ages express their own personal sense of style. Many packs feature multiple compartments that help students stay organized while they carry their books and papers from home to school and back again. Backpacks are, though, they can strain muscles and joints and may cause back pain if they're too heavy or are used incorrectly. Many students carry school backpacks that exceed 10 percent to 15 percent of their body weight, which puts them at risk for back pain and related disorders. Improper backpack use can also lead to poor posture. Girls and younger kids may be especially at risk for backpack-related injuries because they're smaller and may carry loads that are heavier in proportion to their body weight. Carrying backpacks increases the risk of back pain and possibly the risk of back pathology. The prevalence of school children carrying heavy backpacks is extremely high. The daily physical stresses associated with carrying backpacks cause significant forward lean of the head and trunk. It is assumed that daily intermittent abnormal postural adaptations could result in pain and disability in school going children. American Occupational Therapy Association (AOTA) and the America Academy of Pediatrics advise that students should carry no more than $15 \%$ or $10-20 \%$ of their bodyweight.
\end{abstract}

Key Words- Backpack, back pain, children, prevalence, posture

\section{Introduction}

Across the nation, millions of elementary, high school and college students are racing out to the school bus or carrying to their classes with overstuffed backpacks hang over their shoulders. While carrying a backpack to school each morning might seem harmless enough, it can cause some painful back and neck problems for students. Students carry their educational loads mostly in backpacks. The daily physical stresses associated with carrying backpacks cause significant forward lean of the head and trunk. It is assumed that daily discontinuous postural adaptations could result in pain and disability in school going children. Children carrying backpacks for school that load is too much weight are also at risk for short-term and possible long-term health issues.

A backpack should not weigh more than $15 \%$ of a child's total body weight. In other words, a child weighing 85 pounds should not be toting a backpack that weighs more than 12.75 pounds. A child weighing 140 pounds should not carry a pack weighing more than 21 pounds. the weight of a backpack and its contents can cause a person's posture to deteriorate. Heavy school backpacks may also deform natural curves in the back. If the curves are interrupted in the lower and middle back, the result is muscle strain and irritation to the rib cage or spine joints. Much of this suffering is brought by bad habits initiated during our younger years may be because of carrying overweight backpacks to school.

The improper use of backpacks can lead to muscle imbalance that could turn into chronic back and neck problems later in life. In the UK the average backpack weight is $15-20 \%$ of their body weight, and some children carry backpacks as heavy as $30 \%$ to $40 \%$ of their body weight. Many children carrying bags over just one shoulder or very low on their backs. This greatly increases the risk of pain and injury. Local authorities have asked schools to check that backpacks are not overweight and are worn properly and over both shoulders. Students of all levels, carry a schoolbag packed with textbook, notebooks, library books, geometrical and mathematic instruments snacks boxes lunch packs and water bottles and so on. The backpack is one of the several forms of manual load carriage that provides versatility and often used by hikers' backpackers, soldiers, as well as by school children. The backpack is an appropriate way to load the spine closely and symmetrically, while maintaining stability.

Recent worldwide attention has focused on the role of backpacks in the development of children nonspecific low back pain. Research have explored whether there is critical backpack weight to body ratio that if exceeded affects health's studies indicate the incidents of backpacks use by school children in the developed countries is at least $90 \%$. The average loads vary greatly between studies the majority of reports indicate that the loads carried by students greater than the recommended limits. 


\section{Heavy Backpacks For Children}

Overloaded book bags aren't only responsible for back injuries, although that is the main concern but heavy book bags have also been found to cause neck pain, shoulder strain, headaches and a general exhaustion. Book bags that weigh too much may also be to blame for some ankle injuries as they cause their carriers to walk improperly under their oppressive weight. Backpacks can cause pain in the head, neck or face, as well as the hands, the wrists, the elbows, the shoulders, the feet and the ankles. A badly worn backpack can change posture and gait when walking and this compounds the problems. (Singh and Koh 2009) reveled that it is critical to understand the effects of increased backpack weight on children due to their developing bodies. Too much load on the body changes static and dynamic posture as the body tries to overcome the posterior shift in the center of mass.

(Negrini Carobalona2002) reported that the average daily loads of students over a week ranged from $22 \%$ body weight to $27.5 \%$ body weight with one student who carried $46.2 \%$.In this group $38.8 \%$ carried more than $30 \%$ of their body weight.

A study revealed that the weight of materials carried to and from school has significantly increased as curricula changes and extracurricular activities grow, with students sometimes carrying their school materials, sports equipment or instruments around simultaneously (Cavallo et al 2002). In other study founded that with increased educational standards, there is an increased need for assignments outside of the classroom even at younger ages. This means books are getting larger and more abundant along with more outside homework assignments. (Hamilton 2000)

More than 2.5 million elementary school children carry books bags on their shoulder 5 days in a week for the entire school year, this is a large issue that needs to be addressed this problem has been reported internationally. It was difficult to generalize percentages for every school in a country, however, because backpack weight has been associated with several factors, including age, grade, race, school, type of backpack. (Forjuoh et al 2004).

The American Occupational Therapy Association, the American Academy of Orthopaedic Surgeons and the International Chiropractic Pediatric Association suggest that the load should not be more than $10 \%$, the American Physical Therapy Association suggests 15\%, and the American Association of Chiropractors suggests $5-10 \%$ (Cavallo et al 2002).

A study carried out to assess low back pain in school children. The aim of the study was to assess the role of both mechanical and psychosocial factors including emotional and behavioral problems and other somatic pain complaints in childhood low back pain. A population of 1446 school children aged between 11-14 years was selected. Information on potential risk factors for low back pain was sought using a self complete questionnaire and five day bag weight diary. Mechanical factors such as physical activity and school bag weight were not associated with low back pain, however, it was found that strong associations with low back pain were observed for emotional problems, conduct problems, troublesome headaches, abdominal pain, sore throats, and daytime tiredness. Results also suggested that psychosocial factors rather than mechanical factors are more important in low back pain occurring in young populations and could possibly be a reflection of distress in schoolchildren.(Watson KD, Papageogion AC, 2010)

\section{Curvature Of The Spine}

According to the American Occupational Therapy Association heavy backpack worn over one shoulder might cause your child to lean to one side, causing his spine to curve and causing him pain. He can prevent spine curvature, and rounded shoulders, by using both straps and distributing the weight of his backpack evenly across both shoulders.

A study was conducted to assess the prevalence of back pain among school children due to carrying heavy backpacks. Repetitive loading on the spine is known to be a risk factor for lower back pain. The researcher investigated the weight of backpacks carried by 237 children aged between 11-12 years from a school in Milan, Italy, for 3 weeks. The median average load that the children carried was $9.3 \mathrm{~kg}$, and the median maximum load was $11.5 \mathrm{~kg}$, ranging up to $16.3 \mathrm{~kg}$. No limits for the weight of backpacks in schools have been established, but these weights are beyond the allowed load limits for adults. Rates of lower back pain in children are increasing, and these results suggest that a reduction in backpack weight is advisable. ( Hong Y, Cheung2003)

A study investigated that the influence of backpacks on spinal curves, shoulder level, trunk alignment and back pain in adolescent, the result showed that girls suffered from Dorsal Pain (DP) more often and of much more intensity than boys. They also suffered from a decrease in the angle known as Cranio-Cervical angel (CCA) and a shoulder and upper trunk shift. Asymmetrically backpack carrying was associated with high intensity of back pain. Symmetric backpack carrying was highly recommended. (Korvessis et al,in 2005) 
Chansirinukor, W; Wilson, D;et al.(2001) conducted a study to determine whether the backpack ,its position on the spine or time carried affected on adolescents cervical and shoulder posture. Thirteen students were recorded under several load carrying condition. Cervical \& shoulder position angles were calculated and compared. Carrying a backpack weighing $15 \%$ of body weight appeared to be too heavy to maintain standing posture of adolescent. Result revealed that both backpack weight \& time carried influenced cervical \& shoulder posture. These findings have implications for future load carrying studies in adolescent.

Heselgrove,C. Straker,L.et al (2008) was conducted an observational study to assess the perceived school bag load, duration of carriage, and method of transport to school are associated with spinal pain in adolescents. Use and perceived load of school bags as well as spinal pain were measured by questionnaire. The prevalence of back and neck pain were approximately 50\% and 53\% of females reported neck pain compared with $44 \%$ of males. Almost half of participants carried their school bag for more than 30 minutes per day with $85 \%$ carrying their bag over both shoulders. School bags were felt to be heavy by $54 \%$ and to cause fatigue by $51 \%$. Carrying a school bag for more than 30 minutes daily and taking an inactive form of transport to school either by car or bus increased the odds of having both back and neck pain. Neck pain is as common as back pain amongst adolescents. Perceived school bag load, duration of carriage and method of transport to school are associated with back and neck pain. Physical activity in the form of walking or riding to school may offset the potentially provocative effects of prolonged bag carriage and warrants further investigation.

\section{Shoulder and Neck Injury}

According to the American Occupational Therapy Association backpack straps can apply pressure to the blood vessels and nerves in your child's shoulder and neck. The pressure can cause pain and tingling in his arms, hands, legs and neck. Well-padded straps can prevent too much pressure.

A study founded that the pressure under the shoulder straps of backpacks of five males and five females with mean age of 13 years. The result revealed that the contact pressure beneath the shoulder straps was significantly increased at $10 \%, 20 \%$, and $30 \% \mathrm{BW}$. The pressure was significantly higher on the right shoulder than the left shoulder at 10\%, 20\%, and 30\% BW. Contact pressures were essentially zero with an empty backpack. Perceived pain correlated significantly with increasing contact pressure over the range from $10 \%$ to 30\% BW.(Macias et al. 2005).

A study revealed that the pressure underneath the shoulder straps of a mannequin representing a 5 th percentile Canadian armed forces female (weight $52.8 \mathrm{Kg}$ and height $1.55 \mathrm{~m}$ ) as it most closely resembled the anthropometric characteristics of 13 year old school students. A load carriage simulator was used to compare shoulder strap forces and shoulder pressure for 32 combinations of gait speed, backpack weight, load distribution, shoulder strap length and use of a hip-belt. The results showed that the manipulation of backpack weight, hip-belt use and shoulder strap length had a strong effect on shoulder strap tension and shoulder pressure. Backpack weight had the greatest influence on shoulder strap tension and shoulder pressure as the weight of backpack increase the strap tension and shoulder pressure increase as well. When the shoulder strap was loose, the tension and pressure under the shoulder strap decrease.(Mackie et al.2005)

There is a positive relationship between change in the posture during carrying the backpack and changes of trunk position and motion range due to the load being carried which might influence the response of respiration. Children carrying heavy loads have to bend their trunks forward to maintain body posture and balance while walking. Significant increase in forward lean and limit trunk motion range appears to affect the movement of the thorax and seems to reduce the volume of the abdomen as the muscles are contracted in order to gain stability, preventing abdominal breathing. Thus, the only way that the subject could increase oxygen uptake to support the increased metabolic cost might be to use costal breathing and breathing faster.

\section{Muscle Strain}

According to the American Occupational Therapy Association a backpack worn improperly can cause strain or damage to back and stomach muscles. If the backpack is worn loosely, the weight can pull your child backward. If it is not the right size for your child, it will cause uneven distribution of weight and deformed the posture of your child and crest many problems related to posture To protect against muscle strain, adjust shoulder straps, including the waist belt if the backpack has one, and ensure that the backpack rests against your child's lower back.

A study Conducted in New Zealand to assess the weight of schoolbags and the prevalence of musculoskeletal symptoms among 140 students i.e. 70 third form students comprising 35 females and 35 males, and 70 sixth form students comprising 35 females and 35 males. Schoolbag weight for third form students was $13.2 \%$, while for sixth form students it was $10.3 \%$ of their body weight. Musculoskeletal symptoms were reported by $77.1 \%$ of the students. Symptoms were most prevalent in the neck, shoulders, upper back and lower back. Although musculoskeletal symptoms are believed to be multifactorial in origin, the carriage of heavy 
schoolbags is suspected contributory factor and may represent an overlooked daily physical stress. (Whittfield J, Legg SJ, Hedderley2005)

A study revealed that Weight of the backpack is one of numerous contributing factors related to musculoskeletal discomfort among school age students. In additional to the weight of the backpack, duration and frequency of carriage and the manner in which the weight is carried all affect the demands on the musculoskeletal system and may affect the incidence of musculoskeletal pain or discomfort. Currently, school aged children are reporting lower back, shoulder and neck pain. (Lockhart et al. 2004; Mackie et al. 2003)

\section{Chronic Back and Neck Pain}

According to children's Health heavy backpacks can cause upper and lower back pain and neck strain. Poor posture caused by the backpack and the back pain can worsen the problem.

A cross sectional study of self reported back and neck pain associated physical and psychological risk factors was carried out among English school children of University of Surrey, UK. The study set out to identify the associations between ergonomics and other factors with back and neck pain among school children. Self reported questionnaires were used to record health outcomes and potential risk factors in state schools. 679 school children aged between 11-14 years took part. 27\% of children reported having neck pain, 18\% reported having upper back pain, and $22 \%$ reported having low back pain. A forward stepwise logistic regression was performed with pain categories on dependent variables. Neck pain was significantly associated with school furniture features, emotional and conducts problems, family history of low back pain and previous treatment for musculoskeletal disorders. Upper back pain was associated with school bag weight, school furniture features, emotional problems and previous treatment for musculoskeletal disorders. Low back pain was associated with school furniture features, emotional problems, family history and previous injury or accident.

\section{Accidental Injuries}

According to children's Health Students carrying heavy backpacks can cause injuries to others if the backpack hits or falls on a child. A heavy backpack can interfere with the way your child walks, causing him to trip or fall.

\section{Reduce the Injuries from Backpacks-}

- Backpacks should not heavier than $10 \%$ of the children's body weight when packed. .

- Make sure that backpack is light in weight sturdy and sized-matched to the children. It should not larger than children's. Ensure the priority is on comfort, back and shoulder protection and fit rather than good looks and cheap price.

- Always choose a backpack with wide and well padded shoulder straps and with padding at the rear of the backpack where comes into contact with the back and shoulders.

- Always remember that the shoulder straps should be adjustable.. The bottom of the backpack should rest on children's hips - not on their bottom.

- Use both shoulder straps - never slung the pack over one shoulder and use hip straps if available.

- Don't carry the backpack low on the back - A study of 10 healthy children age $12-14$ showed that those who carried the backpack low on the back, created more the pressure on the back and shoulders when wearing it properly positioned high on the back.

- Backpack should be balance the Load. It should be designed like to carry ,balanced, stable and symmetrical load held close to the spine. Parents should make sure that load is distributed properly.

- Show your child the correct way to put on the backpack and wear it properly.

- Make sure that children pack their backpack properly. The various items should be secure and not move around the back.

- Backpack should have many compartments so the children can put heaviest item in the largest compartments near the body.

- When a well designed bag is positioned correctly the back and abdominal muscles, which are amongst strongest muscles in the body, support the weight of the backpack. If the weight is not too heavy the weight is evenly spread over the body and can be supported.

\section{Conclusion}

Children's Health and Healthy Children advise a proper fit and lightening the load. Leave out any items your child does not absolutely need for that day, such as laptops or other electronic devices, extra books or notepads. Also ensure that children bring only important items that they needs for that night's homework. While at school, urge your child to use his locker, desk or other storage areas so he doesn't have to cart around so 
much stuff. Awareness should be created among health care professionals, teachers, parents to restrict backpack load less than 5\% of bodyweight by using school locker shelves. Improper use of backpacks is not healthy for anyone, especially for children who are more susceptible to injury because their bodies are growing and developing. Students, staff, and families need to be educated about backpacks' contribution to back pain and taught appropriate interventions to reduce injury.

\section{References-}

[1] American occupational Therapy Association.Backpack Awareness: One of Many Ways That Occupational Therapists Serve Students. 2009

Available from: <http://www.aota.org/News/Consumer/Backpack08.aspx > [Accessed 6 November 2010]

[2] Cavallo CM, Hlavaty TM, Tamase MG. A pilot study for the development of a primary prevention program: What is the average weight of a fourth grader's backpack? Work. 20, 2002, 137-158.

[3] Chansirinukor W., Wilson D., Grimmer K., et al. Effect of backpack on student measurement of cervical and shoulder posture.Australian J. of physiotherapy.2001.47:110-116

[4] SN, Schuchmann JA, Lane BL.Correlates of heavy backpack use by elementary school children. Public Health. 118, 2004, 532-535.

[5] Hamilton A. Prevention of injuries from improper backpack use in children. Work. 16,2000,177-179.

[6] Haselgrove, C., Straker, L., Smith, A., O’Sullivan, P., Perry, M., \& Sloan, N. Perceived school bag load, duration of carriage, and method of

transport to school are associated with spinal pain in adolescents: an observational study. Australian Journal of Physiotherapy2008 54, 193-200.

[7] Hong Y, Cheung CK.Gait and posture responses to backpack load during level walkingin children. Gait and Posture. 17,2003,28-33.

[8] Korvessis P, koureas G, Zacharatos S, Papazisis Z. Backpacks, back pain, Sagital spinal curves and truck alignment in school adolescent. Spine.2005Jan 15; 30 (2), 247- 255.

[9] Lockhart, R. Jacobs, K. \& Orsmond, G. (2004) Middle school children "s participation in activities and the effects of pain from backpack use on participation. Work, 22, PP.155-168

[10] Mackie, H. Stevenson, J. Reid, S. et al. (2005) The effect of simulated school load carriage on shoulder strap tension forces and shoulder interface pressure. Applied Ergonomics, 36, PP. 199-206

[11] Macias, B. (2005) High Contact Pressure Beneath Backpack Straps of Children Contributes to Pain [Internet]. University of Western Ontario Available from: <www.archpediatrics.com> [Access 28 February 2009].

[12] Negrini S.,Carabalona R.,Sibilla P. Backpack as a daily load for school children. The Lancent [serial online] 1999 Dec 4 [cited 2002 Jan ;354

[13] Singh T, Koh M. Effects of backpack load position on spatiotemporal parameters and trunk forward lean. Gait and Posture. $29,2009,49-53$.

[14] Whittfield J, Legg SJ, Hedderley DI. Schoolbag weight and musculoskeletal symptoms in New Zealand secondary schools, [Online]. $\begin{array}{llllll}2005 & \text { March } & \text { Ocited } & 2010 & \text { Oct } & \text { 20];36(2):[193-8]. }\end{array}$ URL:http://www.chiro.org/LINKS/ABSTRACTS/schoolbagsweightshtml

[15] Watson KD, Papageogion AC, Jones GT, Taylor S, Symmons DPN, Silma AJ, et al. Low back pain in school children:the role of mechanical and psychological factors. BMJ Journals [serial online] 2003 [cited 2010 Oct 29]; 88(1):[12-7]. Available from: URL: http://www.adc.com/content/88/1/12.abstract 